\title{
openheart Novel tech throws knock-out punch to ECG improving GP referral decisions to cardiology
}

\author{
Simone Calcagno, ${ }^{1}$ Giuseppe Biondi-Zoccai, ${ }^{2,3}$ Tatjana Stankovic, ${ }^{4}$ \\ Erzsebet Szabo, ${ }^{5}$ Aniko Berta Szabo, ${ }^{5}$ Istvan Kecskes (1) ${ }^{6}$
}

\begin{abstract}
- Additional supplemental material is published online only. To view, please visit the journal online (http://dx.doi.org/10. 1136/openhrt-2021-001852)
\end{abstract}

To cite: Calcagno $\mathrm{S}$, Biondi-Zoccai G, Stankovic T, et al. Novel tech throws knockout punch to ECG improving GP referral decisions to cardiology. Open Heart 2022;9:e001852. doi:10.1136/

openhrt-2021-001852

Received 9 September 2021 Accepted 7 December 2021

A Check for updates

C Author(s) (or their employer(s)) 2022. Re-use permitted under CC BY-NC. No commercial re-use. See rights and permissions. Published by BMJ.

${ }^{1}$ Division of Cardiology, Santa Maria Goretti Hospital, Latina, Italy

${ }^{2}$ Department of Medical-Surgical Sciences and Biotechnologies, Sapienza University of Rome, Latina, Italy

${ }^{3}$ Mediterranea Cardiocentro, Napoli, Italy

${ }^{4}$ Division of Cardiology, Regional Hospital Dr Radivoj Simonovic Sombor, Sombor, Serbia ${ }^{5}$ Division of Cardiology, Senta General Hospital, Senta, Serbia ${ }^{6}$ Cardiology Research and Scientific Advancements, UVA Research, Toronto, Ontario, Canada

Correspondence to Dr Istvan Kecskes; istvan. kecskes@uvaresearch.com

\section{ABSTRACT}

Purpose In a comparator study, designed with assistance from the Food and Drug Administration, a State-of-the-Art (SOTA) ECG device augmented with automated analysis, the comparator, was compared with a breakthrough technology, Cardio-HART (CHART).

Methods The referral decision defined by physician reading biosignal-based ECG or CHART report were compared for 550 patients, where its performance is calculated against the ground truth referral decision. The ground truth was established by cardiologist consensus based on all the available measurements and findings including echocardiography (ECHO).

Results The results confirmed that CHART analysis was far more effective than ECG only analysis: CHART reduced false negative rates $15.8 \%$ and false positive (FP) rates by $5 \%$, when compared with SOTA ECG devices. General physicians (GP's) using CHART saw their positive diagnosis rate significantly increased, from 10\% to 26\% (260\% increase), and the uncertainty rate significantly decreased, from $\sim 31 \%$ to $\sim 1.9 \%$ (94\% decrease). For cardiology, the study showed that in $98 \%$ of the cases, the CHART report was found to be a good indicator as to what kind of heart problems can be expected (the 'start-point') in the ECHO examination.

Conclusions The study revealed that GP use of CHART resulted in more accurate referrals for cardiology, resulting in fewer true negative or FP-healthy or mildly abnormal patients not in need of ECHO confirmation. The indirect benefit is the reduction in wait-times and in unnecessary and costly testing in secondary care. Moreover, when used as a start-point, CHART can shorten the echocardiograph examination time.

\section{INTRODUCTION}

In the last decade, cardiovascular disease (CVD) has become one of the factors which threaten human health ${ }^{1}$ and is the main cause of death in the world..$^{2-4}$ According to a report presented by the Global Burden of Disease Study, these diseases were responsible for $31.8 \%$ of all deaths worldwide. ${ }^{5}$ Representing a high impact in morbidity and cost to society, there is an urgent need to detect early signs of CVD including heart failure (HF) one of the most difficult to diagnose. ${ }^{6}$

\section{Key questions}

What is already known about this subject?

- In primary healthcare, there is a need for the earIy detection of cardiovascular disease including heart failure, one of the most difficult to diagnose. However, the standard rule-based ECG interpretation provides limited diagnostic evidence for common heart problems.

What does this study add?

- The study indicates that Cardio-HART (CHART) assists the medical professional to determine if the symptoms may be related to cardiac abnormalities or establish some new risks that can lead to cardiac disease if not treated properly. This is especially valuable for patients with recurrent symptoms, which can be difficult to catch with the traditional ECG, or during the regular medical examination.

How might this impact on clinical practice?

- As a result of more accurate and effective diagnostic capabilities, general physicians using CHART were more confident and certain of their decisions both in referrals to secondary care and, just as importantly, knowing when a patient can safely remain in primary care.

- Consequently, patients are more likely to get timely access to care instead of being subjected to further testing and clinical visits to determine their cardiac status and prognosis.

In one multiperspective study 'the difficulties with diagnosis, unclear illness perception, and management disparity' were identified as critical aspects that may impact management of CVD which put in evidence the problem of the effective diagnosis of such life-threatening diseases. $^{7}$

Misdiagnosis or delay in diagnosis of CVD is correlated with lengthened time to treatment, increased hospital stays, including high percentage of readmission, and a higher death rate which brings us to the point that 'the early diagnosis is imperative'. 8

Primary care is the initial contact point ${ }^{9}$ with the patient where CVD is first presented 
and suspected but all too often can go unnoticed or underdiagnosed, sometimes for many months. Underdiagnosis is not uncommon, as studies have found high prevalence rates of CVD in high-risk populations in primary care, such as elders short of breath, type 2 diabetes or chronic obstructive pulmonary diseases (COPD), make the process of identification of CVD all the more difficult. ${ }^{10}$ A review of malpractice claims in the USA revealed that failure to diagnose, which included failure, delay and wrong diagnosis, was responsible for over $41 \%$ of all claims against general physicians (GPs) and $48 \%$ against nurse practitioners. ${ }^{11}$ Further review of claims unmasked a possible common factor, an 'inconclusive ECG'. Compouding the situation, every day, a large number of people with chest pain refer to heart centres with half of them without a real cardiac problem.

The economic burden of CVD on healthcare systems is significant. Hence, correct early diagnosis and appropriate treatment of these patients on initial presentation to their primary care clinic makes it a challenge not only for physicians and hospitals but also for governments, health-insurance companies and health maintenance organisations. ${ }^{12}$

Focusing on this goal, the demand for innovative diagnostic methods for CVD is continuously developing, particularly challenging is the diagnosis of HF, especially in primary care. Therefore, the current diagnostic approach in adults that relies mainly on the use of ECG as the primary diagnostic tool in primary care could be further refined and improved.

Addressing this last objective and to reduce the economic burden from false positive (FP) and false negative (FN) patients, a clinical study was conducted using a new breakthrough medical device that has shown evidence related to improving diagnostic effectiveness in clinical situations, including primary care. Improved diagnostics are achieved through the clever use of novel biosignals processed by Artificial Intelligence techniques to assist GPs in the diagnosis of CVD. It is a direct substitute for ECG devices in the standard of care.

\section{METHODS}

\section{Comparator devices approach}

In each of the study locations, the State-of-the-Art (SOTA) 12-Lead Standard ECG devices that was in daily use was used as the comparator. As Cardio-HART (CHART) includes automated diagnostic processing, the local ECG devices lacking such functionality, were also augmented with the leading automated diagnostic algorithms to assist GPs in interpretation of ECG signals. The resulting output is in the form of a diagnostic report.

CHART uses novel technology in the analysis of the heart biosignals. The CHART system differs from the SOTA ECG devices in that it combines the functionality of three heart devices into one, including ECG, Echocardiography (ECHO) and Auscultation. As a result, it can detect 143 heart parameters and 47 heart findings associated with $\sim 95 \%$ of all common heart diseases prevalent in clinical situations. The resulting output is in the form of an easy-to-grasp report for use by clinicians.

This study demonstrates GP diagnostic effectiveness through a direct clinical comparison between the comparator ECG devices, representing the current standard of care and the CHART device, a breakthrough technology.

\section{Study design}

The study was conducted as a multicentre clinical study to confirm the functional and operational aspects between two medical devices competing head-to-head against each other, CHART versus SOTA ECG, in clinical practice to determine which provided the most beneficial clinical decision support for GPs and best outcomes for patients. The results for each patient were verified and validated in accordance with its intended performance by a separate team of cardiologists to ensure an accurate ground truth.

Each patient willingly gave their consent, in writing. Both devices are non-invasive and were considered low risk.

The goal was to determine the utility of CHART and its usability for its intended use, in a clinical environment, by its intended users, in a study population representative of the target population, in direct comparison to a SOTA ECG device used within the Standard of Care for Primary Care. The study was designed to collect the data to confirm the safety and effectiveness of the CHART system when compared with ECG. A total of 550 patients were recruited into the CUUS, and their clinical results evaluated to measure the diagnostic and decision support capability of the SOTA ECG report when directly compared with the CHART report.

The results confirm that in many ways CHART analysis is far more effective than ECG only analysis. FN rates are significantly decreased (CHART produced a $15.8 \%$ decrease in $\mathrm{FN}$ ) and $\mathrm{FP}$ rates decreased by $5 \%$ (FP in the patient referral decision by GP as compared with ECGonly based decisions). The data collected would confirm the hypothesis that CHART analysis is more effective than ECG only analysis in assisting the general practitioner (GP) in determining their referral decision (Send/Don't Send) and the basis for it.

The setup for the study was to assign two independent GPs to each patient. Each GP would independently examine the same patient then render their diagnosis based on the device they were assigned in the protocol. One GP would be using CHART and the other GP would be using their local SOTA ECG device augmented with automated algorithmic assessment. Each patient would first be tested using the ECG device then the CHART device. Two diagnostic reports were then produced, one for each protocol. Each GP, based on their protocol device, was to diagnose the patient's cardiac status and determine a course of action. In this way the patient is the control, being the same patient for both GPs. At the mid-point of the study, the GPs were switched to the other device/protocol. 


\section{Table 1 Referral decision tree}

\section{Send/don't binary decision}

Detailed referral decision

\begin{tabular}{ll}
\hline Not refer - don't send & 1. No Action \\
& 2. Watch 12 months \\
& 3. Watch 6 months \\
& 4. Watch 3 months \\
5. Not sure (no evidence for decision)
\end{tabular}

Not sure (no evidence for

decision)

2021 Cardio-Phoenix.

The first decision by the GP's was to render a diagnosis based on their understanding of the patient's cardiac status. From this they were to determine whether the patient was to be referred to cardiology or not. This was the 'Send'/'Don't Send' decision. If Send, they were to indicate with what priority, whether urgent, immediate or routine. If Don't Send, they were to indicate whether patient was normal, or be indicated for a control visit, at 3,6 or 12 months.

See online supplemental file 1 for more details.

\section{Primary hypothesis}

The goal was to directly compare two cardiac diagnostic systems to each other to characterise their effectiveness and utility in providing diagnostic assistance to GPs. The referral decision was used to measuring the effectiveness of the decision, see table 1.

Referral decisions were made by two different GP's, based on either ECG-only or CHART analysis, for the same patient and evaluated through statistical analysis of comparison to establish the certainty of the decisions and understanding of the diagnosis.

\section{RESULTS}

\section{Patient statistics}

The study involved both male and female patients, distributed equally, with at least three risk factors for heart disease, ${ }^{13}$ attending a primary care clinic for health reasons, including annual physical examination, that is, a typical primary care setting. The minimum target sample size was 500 patients of which at least $15 \%$ should be considered as healthy patients (no risk factors). The age distribution is: 61 patients between 20 and 40 years, 130 between 41 and 55 years, 156 between 56 and 65 years, 148 between 66 and 75 years and 52 above 76 years. The obesity distribution is: $6.2 \%$ underweight, $35.8 \%$ normal, $34.7 \%$ overweight and $23.3 \%$ obese.

\section{Reference referral decision}

The reference referral decision defined by cardiologyconsensus was based on three factors, risk, ECG and an ECHO examination (transthoracic echocardiogram). Each of the ground truth decisions was established by a minimum of three independent cardiologists. The average consensus performance of the binary referral decision (cardiologist's agreement for Send/Don't) was $87.5 \%$ and for priority/watch detailed decision was $60.6 \%$. These numbers were expected and comparable with the known measurement variability of ECHO assessment $^{1415}$ or ECG. ${ }^{16}$

The overall reference send rate was $43.0 \%$, which is an important cardiac condition property of the included patient population. This referral to cardiologist care rate is similar to that of other studies, confirmed by the literature, with a typical range of $30 \%-50 \% .^{17-20}$

\section{Referral decision results}

The GP decision referral performance was based on either the ECG or CHART reports, presented in table 2. In the statistical calculation for the reference decision was the consensus-based ground truth.

The significance is derived from confidence intervals: if the observed value is higher than the upper confidence value, then it considered a significant increase. Less significant increase means there is an increase in the observed value, but it is not higher than the upper confidence value.

Figure 1 illustrates the performance evaluation and comparison of GP referral decision between ECG-based and CHART-based answers. CHART-based decisions showed higher accuracy compared with ECG-based decisions, especially its sensitivity which CHART showed a big increase. CHART also decreased the FP rate from $21 \%$ to $16 \%$, and $\mathrm{FN}$ rate from $50 \%$ to $34 \%$. The significant increase of positive predictive value, negative predictive value, kappa, area under the curve and LR+ and decrease of LR- confirms the benefit of using the CHART report over the ECG only report.

The positive rate (PR) or send rate by GPs is similar between ECG and CHART reports (PR\% $=33 \%$ by ECG and $\mathrm{PR} \%=36 \%$ by CHART), however CHART's send rate is closer to the ground truth $(\mathrm{PREV} \%=43 \%)$. This means that the send rate of the GP referral decision using CHART met with the cardiologist expectations as confirmed by the ground truth. This includes a reduction in FP but also an increase in TP from FNs that were missed in ECG-based decisions.

Interestingly, the overall number of patients referred didn't really change, as normal patients are replaced with patients with potentially abnormal cardiac function.

\section{GP and referral cardiologist diagnosis results}

The CHART assessment was performed twice, first in primary care (CHART\#1 and ECG reports), and again in cardiology care (CHART\#2 report), prior to the ECHO 
Table 2 Performance of GP referral decision on ECG and CHART reports compared with by consensus ground truth

\begin{tabular}{|c|c|c|c|c|c|c|c|}
\hline \multirow[b]{2}{*}{ Metric } & \multicolumn{3}{|c|}{$\begin{array}{l}\text { ECG report } \\
\text { Performance }\end{array}$} & \multicolumn{3}{|c|}{$\begin{array}{l}\text { CHART report } \\
\text { Performance }\end{array}$} & \multirow{2}{*}{$\begin{array}{l}\text { CHART compare to } \\
\text { ECG } \\
\text { Hypothesis test with } \\
95 \% \mathrm{Cl}\end{array}$} \\
\hline & $\begin{array}{l}\text { Lower } \\
\text { conf. \% }\end{array}$ & $\begin{array}{l}\text { Observed } \\
\text { value } \%\end{array}$ & $\begin{array}{l}\text { Upper } \\
\text { conf. \% }\end{array}$ & $\begin{array}{l}\text { Lower } \\
\text { conf. \% }\end{array}$ & $\begin{array}{l}\text { Observed } \\
\text { value } \%\end{array}$ & $\begin{array}{l}\text { Upper } \\
\text { conf. \% }\end{array}$ & \\
\hline SE\% & 42.00 & 48.52 & 55.08 & 57.67 & 64.14 & 70.24 & Significant increase \\
\hline SP\% & 73.63 & 78.59 & 83.01 & 79.49 & 84.03 & 87.91 & Significant increase \\
\hline PPV\% & 55.74 & 63.19 & 70.20 & 68.70 & 75.25 & 81.04 & Significant increase \\
\hline NPV\% & 61.78 & 66.85 & 71.64 & 70.71 & 75.57 & 80.00 & Significant increase \\
\hline K\% & 22.52 & 27.90 & 33.71 & 42.89 & 49.04 & 55.25 & Significant increase \\
\hline AUC\% & 66.02 & 70.80 & 75.02 & 74.44 & 79.13 & 83.03 & Significant increase \\
\hline LR+ & 1.84 & 2.27 & 2.86 & 3.13 & 4.01 & 5.30 & Significant increase \\
\hline LR- & 0.70 & 0.65 & 0.62 & 0.45 & 0.43 & 0.41 & Significant decrease \\
\hline PR\% & 29.17 & 33.09 & 37.20 & 32.69 & 36.73 & 40.91 & Less significant increase \\
\hline
\end{tabular}

Better performance values are shown in bold.

Confusion matrices and performance equations available in online supplemental file 1.

AUC, area under the curve; CHART, Cardio-HART; GP, general practitioner; K, kappa statistics; LR+, positive Likelihood Ratio; LR-, Negative Likelihood Ratio; NPV, negative predictive value; PPV, positive predictive value; PR, positive rate; SE, sensitivity; SP, specificity.

examination. The typical delay between the two tests is 3-15 days.

The relevant CVD diagnosis was compared between four cases: (1) GP diagnoses on ECG report, (2) GP diagnosis on CHART\#1 report, (3) the over-reading cardiologist (ORC) diagnosis that included ECG, then CHART\#1, and (4) the referral cardiologist (RC) diagnoses that included ECG, CHART\#1 and CHART\#2 report. Table 3 lists the diagnostic findings based on either ECG or CHART reports.

Figure 2 summarises the three types of diagnosis, where the three colours represent the rate of 'absence', 'presence' and 'not-sure' answers. The GP's positive (number of abnormal or presence) diagnosis rate shows a significant increase, from $9.8 \%-23.6 \%$ to $28.8 \%$ by CHART compared with ECG based assessment. The uncertainty rate measured by the number of 'not sure' answersshow a significant decreased, from $30.9-1.7 \%$ to $2.1 \%$.

The RC's uncertainty rate on CHART\#2 is small, but significantly, is similar to that of the GP on CHART\#1. The RC's positive diagnosis rate on CHART\#2 is (23.6\%) which is in line to GP's positive diagnosis rate on CHART\#1 $(28.8 \%)$, which is significantly more in agreement when compared with ECG at $(9.8 \%)$.

A notable outcome in table 3 , between arrhythmia and ischaemia categories is that being typically ECG-based

\begin{tabular}{|c|c|c|c|}
\hline \multicolumn{4}{|c|}{ GP binary decision on ECG } \\
\hline & $\sim$ Dont & $\sim$ Send & \#sum \\
\hline \#Dont & 246 & 67 & 313 \\
\hline \#Send & 122 & 115 & 237 \\
\hline sum & 368 & 182 & 550 \\
\hline
\end{tabular}

B

\begin{tabular}{|c|c|c|c|}
\hline & Dont & Send & \#sum \\
\hline \#Dont & 263 & 50 & 313 \\
\hline \#Send & 85 & 152 & 237 \\
\hline sum & 348 & 202 & 550 \\
\hline
\end{tabular}

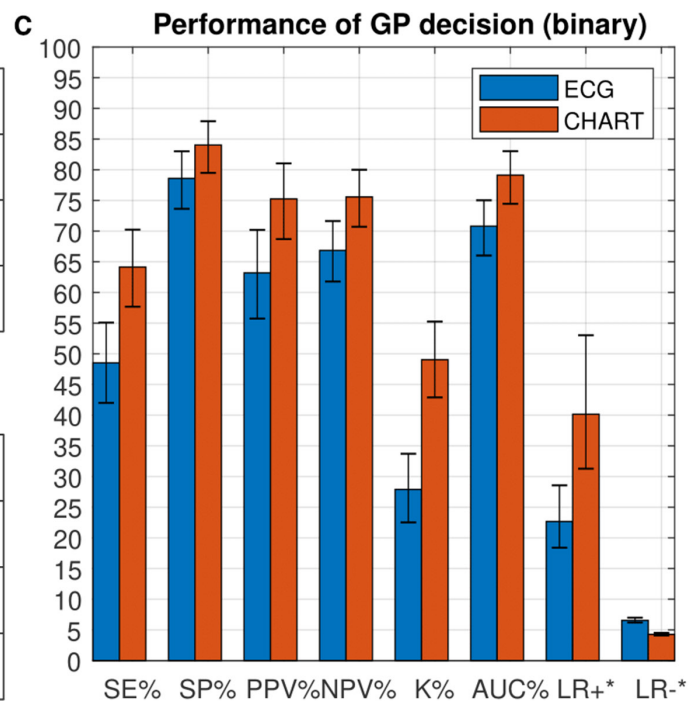

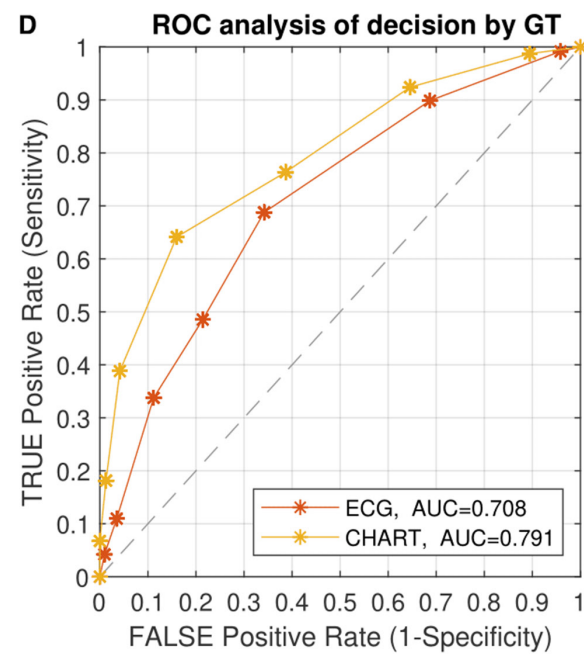

Figure 1 Performance of GP decision by consensus ground truth. (A) Binary confusion matrix on ECG report, (B) binary confusion matrix on CHART report, (C) performance metrics with confidence intervals, (D) estimated ROC curve based on the detailed referral decision. AUC, area under the curve; CHART, Cardio-HART; GT, ground truth; GP, general practitioner; LR+, positive likelihood ratio; LR-, negative likelihood ratio; NPV, negative per cent agreement; PPV, positive per cent agreement; $\mathrm{ROC}$, receiver operating characteristic. 
Table 3 Diagnostic points used in CUUS at GP and RC diagnosis forms

\begin{tabular}{|c|c|c|c|}
\hline \multirow{2}{*}{$\begin{array}{l}\text { Diagnostic } \\
\text { points }\end{array}$} & \multirow[b]{2}{*}{ Description } & \multicolumn{2}{|l|}{ Supported by } \\
\hline & & ECG & CHART \\
\hline Arrhythmia, blocks & $\begin{array}{l}\text { Rhythm problem, } \\
\text { Premature complex } \\
\text { beats, } \\
\text { Heart blocks, } \\
\text { Axis deviation } \\
\text { Other: pacemaker, etc. }\end{array}$ & Yes & Yes \\
\hline LV dysfunction & $\begin{array}{l}\text { Left Ventricular Systolic } \\
\text { and } \\
\text { Diastolic Dysfunction }\end{array}$ & No & $\begin{array}{l}\text { HART LVSD } \\
\text { HART LVDD }\end{array}$ \\
\hline Ischaemia & $\begin{array}{l}\text { ST/STT deviation } \\
\text { QT interval } \\
\text { T-wave abnormality } \\
\text { Wall motion abnormality } \\
\text { Myocardial Infarction }\end{array}$ & $\begin{array}{l}\text { Yes } \\
\text { Yes } \\
\text { Yes } \\
\text { No } \\
\text { Yes/partial }\end{array}$ & $\begin{array}{l}\text { Yes } \\
\text { Yes } \\
\text { Yes } \\
\text { HART WMA } \\
\text { Yes+WMA }\end{array}$ \\
\hline $\begin{array}{l}\text { Structural } \\
\text { abnormality }\end{array}$ & $\begin{array}{l}\text { LV Hypertrophy } \\
\text { LA Enlargement } \\
\text { RA Enlargement } \\
\text { RV Enlargement } \\
\text { Cardiomyopathy }\end{array}$ & $\begin{array}{l}\text { LVH (Low sensitivity) } \\
\text { LAE (Low sensitivity) } \\
\text { RAE (Low sensitivity) } \\
\text { RVH (Low sensitivity) } \\
\text { LVH (Low sensitivity) }\end{array}$ & $\begin{array}{l}\text { HART LVH } \\
\text { HART LAE } \\
\text { HART RAE } \\
\text { HART RVE } \\
\text { HART DCM }\end{array}$ \\
\hline Valve disease & $\begin{array}{l}\text { Aortic Stenosis and } \\
\text { Insufficiency } \\
\text { Mitral Stenosis and } \\
\text { Insufficiency } \\
\text { Tricuspid Insufficiency } \\
\text { Pulmonary hypertension }\end{array}$ & No & $\begin{array}{l}\text { HART AS } \\
\text { HART MS } \\
\text { HART TR } \\
\text { HART PH }\end{array}$ \\
\hline $\begin{array}{l}\text { PCG-based murmur } \\
\text { presence }\end{array}$ & $\begin{array}{l}\text { S1 splitting } \\
\text { Systolic and diastolic } \\
\text { murmur } \\
\text { Ejection sound } \\
\text { Third and Fourth sound }\end{array}$ & No & $\begin{array}{l}\text { Yes, CHART } \\
\text { PCG }\end{array}$ \\
\hline $\begin{array}{l}\text { MCG/PCG based } \\
\text { Systolic time } \\
\text { interval } \\
\text { Abnormalities }\end{array}$ & $\begin{array}{l}\text { EMAT, PEP, LVET interval } \\
\text { IVCT, IVRT intervals } \\
\text { SPI and MPI indexes }\end{array}$ & No & $\begin{array}{l}\text { Yes, CHART } \\
\text { MCG }\end{array}$ \\
\hline
\end{tabular}

CHART, Cardio-HART; CUUS, Clinical Utility and Usability Study; EMAT, electro-mechanical activation time; GP, general practitioner; IVCT, isovolumic contraction time; IVRT, isovolumic relaxation time; LA, left atrial; LAE, left atrial enlargement; LV, left ventricular; LVDD, LV diastolic dysfunction; LVET, left ventricular ejection time ; LVSD, LV systolic dysfunction; MCG, mechano-physiological signal; MPI, myocardial performance index; PCG, phonocardiogram; PEP, pre-ejection period; RA, right atrial; RAE, right atrial enlargement; RC, referral cardiologist; RV, right ventricular; RVH, right ventricular hypertrophy; SPI, systolic performance index; WMA, LV wall motion abnormality.

findings, they showed similar results between ECG and CHART, but with CHART showing much less uncertainty when used. In the structural abnormality category the results are mixed, when using ECG there was high uncertainty, but when using CHART there was high certainty (decreased uncertainty). These results are not surprising as ECG has low sensitivity for these conditions, that are typically confirmed with ECHO.

The rest of the diagnostic points (valve disease, murmurs and systolic time interval findings) are only supported by CHART, which dispels all the uncertainties observed with use of ECG.

\section{Decision agreement between GP, ORC and rC}

In the agreement statistics, the GP to ORC and GP to the $\mathrm{RC}$ decision were compared on the same patient, based on their ECG and CHART reports, see table 4.

In the case of CHART, the decision agreement between GP and ORC is significantly higher compared with ECG (figure 3A). This suggest that when CHART is available to GPs, the over-reading role might be less necessary. Notably also, the agreement comparison between GP and ORC is also similar to that of GP and RC (figure 3B). In clinical practice, the consequences of this means that RC's will get fewer Normal patients, patient that don't need echocardiology.

\section{Physician interview results}

Comparison between $\mathrm{ORC}$ and $\mathrm{RC}$

ORC and RC were asked to compare ECG and CHART reports. The following results were observed based on 522 answers set on 8 questions, see table 5 . The results for ORC and RC are very similar in all the questions, they confirm each other.

The benefit of CHART is twofold, on the one hand, it provides better cardiac status diagnostics, and on the other hand it provides more reliability due to its wider range of parameters and findings. As such, CHART increases the certainty (reduces uncertainty) of decisions aided by its findings.

\section{Chart as start point for ECHO}

$\mathrm{RC}$ were asked to evaluate the CHART report to show how useful it could be in providing an appropriate start point to an ECHO examination, thereby avoiding a "cold start'. The following results were observed based on 391 answers set on 3 questions, see table 5 .

CHART-findings based on ECHO-findings are a good indicator as to what kind of heart problems, comorbidities, that can be expected (the 'start point') during the ECHO examination. Aware of the big picture and range of comorbidities can help shorten examination times and reduce the probability of undiagnosed or misdiagnosed conditions.

\section{DISCUSSION}

GPs in Primary Care can be meaningful contributors to diagnosing heart disease when patients first present, enabling earlier detection of (CVD) onset and reduction in unnecessary and costly referrals to Cardiology. This will have significant benefits in terms of reduced waittime, and more timely access to treatment.

The value of CHART stems from its HART/ECHOfindings as they bring to primary care morphological and functional characteristics to heart disease able to identify cardiac conditions that are typically only diagnosed by ECHO. This effectively bridges the technological diagnostic gap between use of ECG in primary care and use of ECG and ECHO in secondary care. 

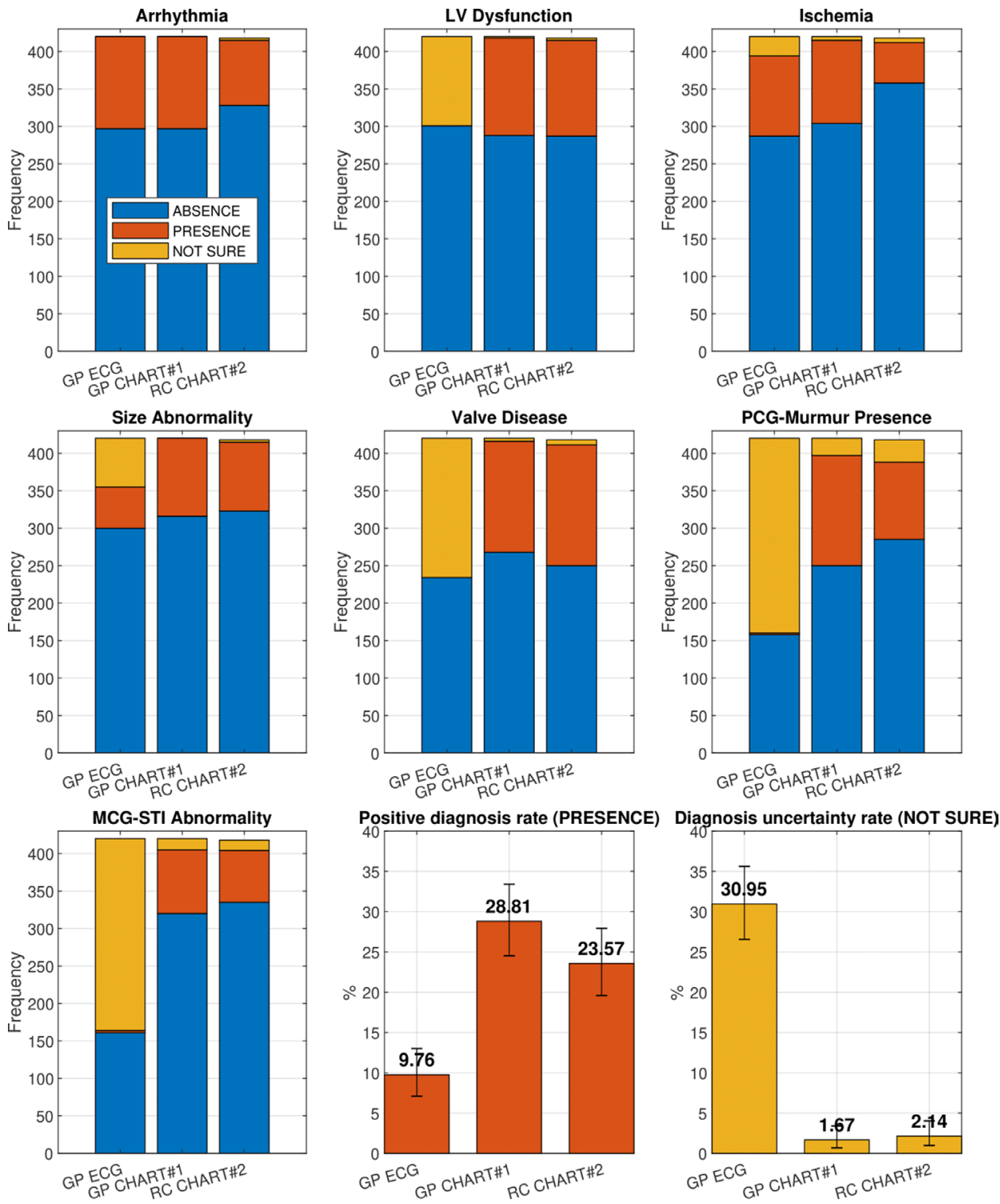

Figure 2 Statistics of the medical findings diagnosis between the tree groups: GP on ECG, GP on chart and RC on chart. CHART, Cardio-HART; GP, general practitioner; RC, referral cardiologist.

Part of the GP's tasks was to indicate a priority when a patient was referred, 'send', to cardiology. A beneficial consequence of the use of ECHO-findings by CHART, is that they serve to establish a starting point for prioritisation of patients based on medical justification based on disease severity, urgency. Typically, referrals to secondary care are on a first come first serve basis, with patients in greater need provided a higher priority only when symptoms have become overt or acute. Such is the case of acute $\mathrm{HF}$, where over $79 \%$ of all cases are typically diagnosed in Hospital. Yet, in the 6 months prior to their hospital diagnosis, $41 \%$ of these patients had visited Primary Care having at least one of three key HF symptoms that should have triggered an earlier assessment. ${ }^{21}$

The surprise consistency in diagnostic accuracy between the GP and the ORC (positive per cent agreement, $\mathrm{PPA}=67 \%$, negative per cent agreement, $\mathrm{NPA}=81 \%$ ), compared with ECG-based assessment (PPA=52\%,
$\mathrm{NPA}=77 \%$ ) suggests that the over-reading role might be reconsidered when CHART is present. The pandemic has shown that change is needed given the budget pressures placed on healthcare, further study is warranted.

In the study, RCs performed a second CHART examination on initial patient presentation to cardiology. This allowed cardiologists to determine whether ECHO confirmation as indicated by the GP was in fact warranted. Replacing the standard ECG with CHART on patient presentation to cardiology would have several benefits. First, it would help identify patients that don't need ECHO, currently a massive contributor to increased wait-times and backlogs. Second, it would help avoid a 'cold-start', as it is not uncommon for patients to present to cardiology with insufficient referral information and so help focus the cardiologist on a specific region of interest. For example, unless the referring GP specifically suggests HF in the referral, Cardiologists do not 


\begin{tabular}{|c|c|c|c|c|c|c|c|c|}
\hline & \multirow[b]{2}{*}{ Metric } & \multicolumn{3}{|c|}{$\begin{array}{l}\text { ECG report } \\
\text { performance }\end{array}$} & \multicolumn{3}{|c|}{$\begin{array}{l}\text { CHART report } \\
\text { performance }\end{array}$} & \multirow{2}{*}{$\begin{array}{l}\text { CHART } \\
\text { compare to ECG } \\
\text { hypothesis test } \\
\text { with } 95 \% \mathrm{Cl}\end{array}$} \\
\hline & & $\begin{array}{l}\text { Lower } \\
\text { conf. \% }\end{array}$ & $\begin{array}{l}\text { Observed } \\
\text { value } \%\end{array}$ & $\begin{array}{l}\text { Upper } \\
\text { conf. \% }\end{array}$ & $\begin{array}{l}\text { Lower } \\
\text { conf. \% }\end{array}$ & $\begin{array}{l}\text { Observed } \\
\text { value } \%\end{array}$ & $\begin{array}{l}\text { Upper } \\
\text { conf. \% }\end{array}$ & \\
\hline \multirow{6}{*}{$\begin{array}{l}\text { ORC versus } \\
\text { GP }\end{array}$} & PPA\% & 44.8 & 52.0 & 59.1 & 60.1 & 67.0 & 73.4 & Significant increase \\
\hline & NPA\% $\%$ & 72.9 & 77.7 & 81.9 & 76.8 & 81.3 & 85.3 & $\begin{array}{l}\text { Not significant } \\
\text { increase }\end{array}$ \\
\hline & PPV\% & 49.6 & 57.1 & 64.4 & 61.4 & 68.3 & 74.7 & Significant increase \\
\hline & NPV\% & 69.0 & 73.8 & 78.3 & 75.8 & 80.4 & 84.5 & Significant increase \\
\hline & $\mathrm{K} \%$ & 24.5 & 30.2 & 36.2 & 42.2 & 48.5 & 54.7 & Significant increase \\
\hline & PR\% & 29.2 & 33.2 & 37.3 & 32.8 & 36.8 & 41.0 & $\begin{array}{l}\text { Not significant } \\
\text { increase }\end{array}$ \\
\hline \multirow{6}{*}{$\begin{array}{l}\mathrm{RC} \text { versus } \\
\mathrm{GP}\end{array}$} & PPA\% & 48.0 & 55.7 & 63.2 & 60.6 & 67.7 & 74.3 & Significant increase \\
\hline & NPA\% & 73.7 & 78.5 & 82.7 & 75.6 & 80.4 & 84.5 & $\begin{array}{l}\text { Not significant } \\
\text { increase }\end{array}$ \\
\hline & PPV\% & 49.5 & 57.3 & 64.8 & 59.5 & 66.7 & 73.3 & Significant increase \\
\hline & NPV\% & 72.5 & 77.3 & 81.6 & 76.4 & 81.1 & 85.2 & $\begin{array}{l}\text { Not significant } \\
\text { increase }\end{array}$ \\
\hline & $\mathrm{K} \%$ & 28.2 & 34.4 & 40.9 & 41.5 & 47.9 & 54.4 & Significant increase \\
\hline & PR\% & 29.2 & 33.2 & 37.5 & 33.1 & 37.3 & 41.6 & $\begin{array}{l}\text { Not significant } \\
\text { increase }\end{array}$ \\
\hline
\end{tabular}

Better performance values are shown in bold.

CHART, Cardio-HART; GP, general practitioner; K, kappa statistics; NPA, negative per cent agreement; NPV, negative predictive value; ORC, over-reading cardiologist; PPA, positive per cent agreement; PPV, positive predictive value; PR, positive rate; RC, referral cardiologist.

routinely consider HF during the Echo examination. As CHART can provide an understanding of both left heart side abnormalities (left ventricular hypertrophy, left atrial enlargement, mitral regurgitation and wall motion abnormality) and right heart side abnormalities (right ventricular enlargement, right atrial enlargement, tricuspid rergurgitation and pulmonary hypertension), a first use on initial patient presentation to cardiology can help identify areas of concern, including HF.
Accordingly, CHART is not a substitute for ECHO, nor is it intended as a surrogate to cardiologists but rather as a valid support for GPs in clinical settings. Yet when ECHO is not yet available, it can assist GP's with determining patient pathway with more confidence and immediacy.

\section{Limitations}

The right side of the heart is less represented by the included ECHO-parameters and even less so by ECG,
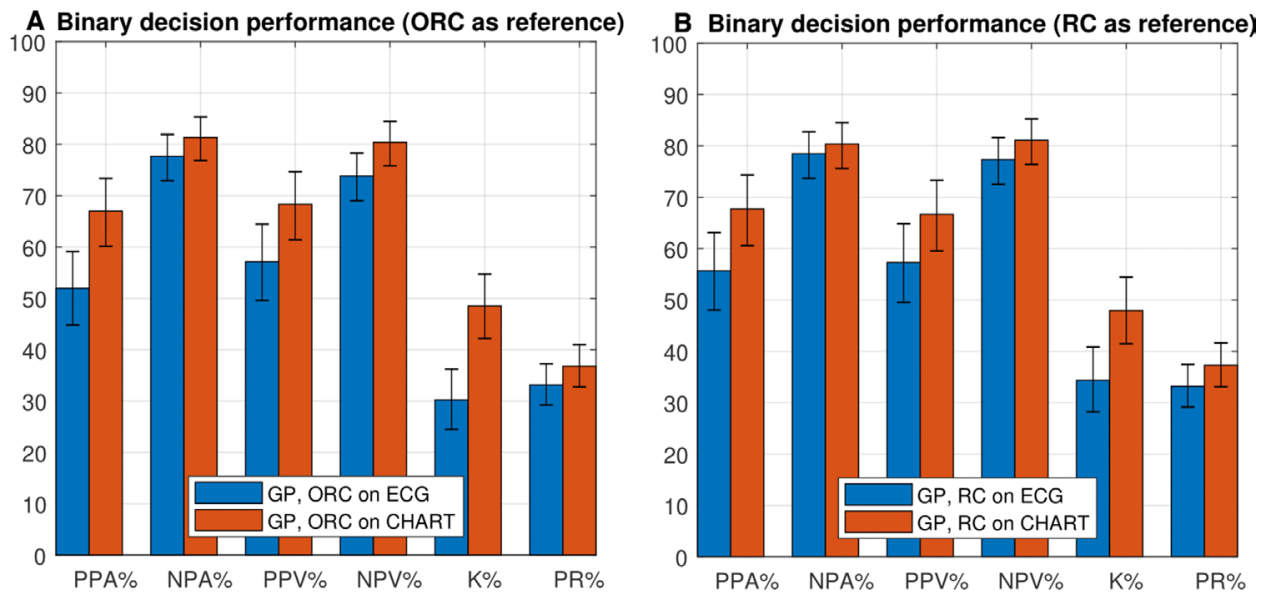

Figure 3 Agreement performance analysis of (A) GP decision versus ORC decision, (B) GP decision versus RC decision. CHART, Cardio-HART; GP, general practitioner; NPA, negative per cent agreement; NPV, negative predictive value; ORC, over-reading cardiologist; PPA, positive per cent agreement; PPV, positive predictive value; PR, positive rate; RC, referral cardiologist. 
Table 5 Interview results for comparison ECG over CHART questions and CHART as a start point for ECG questions

\begin{tabular}{|c|c|}
\hline Answer & \\
\hline $\begin{array}{l}\text { Yes } \\
\text { (Improve) }\end{array}$ & $\begin{array}{l}\text { No (not- } \\
\text { improve) }\end{array}$ \\
\hline ORC RC & ORC RC \\
\hline
\end{tabular}

\section{Interview question for ECG over CHART}

Summary

\begin{tabular}{|c|c|c|c|}
\hline $\begin{array}{l}\text { When comparing a patient's CHART\#1 report to the ECG-only } \\
\text { report, your understanding of the patient's cardiac status: }\end{array}$ & $70.4 \% 64.4 \%$ & $29.6 \% 35.6 \%$ & \multirow{3}{*}{$\begin{array}{l}\text { CHART improves the understanding of patient cardiac } \\
\text { status in } 64 \%-70 \% \text { and increases the certainty of } \\
\text { referral decision in } 80 \% \text {. }\end{array}$} \\
\hline $\begin{array}{l}\text { Did CHART\#1 help you to better understand the cardiac status } \\
\text { of the patient, compared with ECG-only? }\end{array}$ & $76.0 \% 76.6$ & $24.0 \% 23.4 \%$ & \\
\hline $\begin{array}{l}\text { Were you more certain of your decision with CHART\#1 then } \\
\text { with the ECG-only report? }\end{array}$ & $79.9 \% 79.9 \%$ & $20.1 \% 20.1 \%$ & \\
\hline $\begin{array}{l}\text { Would you change any part of your initial ECG-only diagnosis } \\
\text { after comparing it to CHART\#1? }\end{array}$ & $20.3 \% 18.8 \%$ & $79.7 \% 81.2 \%$ & \multirow{2}{*}{$\begin{array}{l}\text { ORC and } \mathrm{RC} \text { change their ECG-based referral based on } \\
\text { the CHART report } 19 \%-22 \%\end{array}$} \\
\hline $\begin{array}{l}\text { Did you change the Send/Don't decision in CHART\#1 from } \\
\text { ECG-only? }\end{array}$ & $22.4 \% 19.5 \%$ & $77.6 \% 80.5 \%$ & \\
\hline Did the "Send Priority" change in CHART\#1? & $49.1 \% 48.7 \%$ & $50.9 \% 51.3 \%$ & $\begin{array}{l}\text { In case of consistent 'Send' decision from ECG to CHART, } \\
\text { CHART change the referral priority in } 49 \% \text {. }\end{array}$ \\
\hline Did the Treatment Options in CHART\#1 change? & $14.7 \% \quad 9.3 \%$ & $85.3 \% 90.7 \%$ & \multirow{2}{*}{$\begin{array}{l}\text { In case of consistent 'Don't' decision from ECG to CHART, } \\
\text { CHART changed the watch option priority } 11 \%-16 \% \text {. }\end{array}$} \\
\hline Did the Watch option in CHART\#1 change? & $16.1 \% 11.7 \%$ & $83.9 \% 88.3 \%$ & \\
\hline $\begin{array}{l}\text { Interview Question for } \\
\text { CHART as a start point for ECHO }\end{array}$ & Yes & No & Summary \\
\hline Does Echo confirm CHART results? & $94.1 \%$ & $5.9 \%$ & $\begin{array}{l}\text { In } 94 \% \text { of cases the CHART diagnosis was confirmed by } \\
\text { the ECHO examination }\end{array}$ \\
\hline Did CHART provide appropriate start point for examination? & $98.7 \%$ & $1.3 \%$ & $\begin{array}{l}\text { RC found CHART as useful to determining an appropriate } \\
\text { start point in } 98 \%\end{array}$ \\
\hline $\begin{array}{l}\text { Did CHART help provide a better understanding of patient } \\
\text { cardiac status compared with ECG-only analysis? }\end{array}$ & $97.7 \%$ & $2.3 \%$ & $\begin{array}{l}\text { CHART provides a better understanding of patient cardiac } \\
\text { status in } 97.7 \% \text { compared with ECG. }\end{array}$ \\
\hline
\end{tabular}

CHART, Cardio-HART; ECHO, echocardiography; ORC, over-reading cardiologist; RC, referral cardiologist.

as such their place in the statistical results is limited. Nonetheless, right-side heart disease and its structural, functional abnormalities and related pulmonary disease comorbidities (COPD, COVID-19) have attracted growing attention. Right-heart side study through a biosignal approach shows strong potential. Further research is warranted to investigate in more detail the relationship between HF categories and right-side HF through the window of biosignals, risk factors, detectable abnormalities, COPD and other comorbidities and symptoms.

\section{CONCLUSIONS}

Originally designed with extensive inputs and specific design criteria from the Food and Drug Administration, ${ }^{22}{ }^{23}$ the results of the CUUS study showed that the beneficial implications of this novel tech in primary care are significant, both from a clinical and economic perspective. The study results shows that CHART has the potential to enable effective widespread screening of patients for the early detection of CVD onset and resolve many 'inconclusive ECG' results thereby reducing both $\mathrm{FN}$ and $\mathrm{FP}$ in referral decisions.

Twitter Giuseppe Biondi-Zoccai @gbiondizoccai

Contributors SC and GBZ unrelated and independent of the clinical study, completed an independent review of the results of the clinical study. TS was the principal investigator and assisted with data and verification of ground truth. ES and $A B S$ assisted with data and verification of ground truth. IK assisted in the statistical assembly and data preparations. IK is the guarantor, who is responsible for the overall content.

Funding Original Study was Sponsored by Cardio-Phoenix, and conducted by UVA Research and Development d.0.0. Serbia.

Competing interests GBZ: disclosure: consulted for Cardionovum, CrannMed, InnovHeart, Meditrial, Opsens Medical and Replycare. IK: disclosure: Director, UVA research, no other industry connections. TS: no relationships to Industry. ES: no relationship to industry $A B S$, no relationship to industry.

Patient consent for publication Not applicable.

Ethics approval This study involves human participants and was approved by Ethics Committee of General Hospital Vrsac (ID: 01-759/2)/Ethics Committee of General Hospital Sombor (ID: 31-2707/2018-2). Participants gave informed consent to participate in the study before taking part.

Provenance and peer review Not commissioned; externally peer reviewed.

Data availability statement Data are available on reasonable request. The clinical data are for legitimate purposes on request. The Official Study Report can be obtained on request: info@cardiophoenix.com

Open access This is an open access article distributed in accordance with the Creative Commons Attribution Non Commercial (CC BY-NC 4.0) license, which permits others to distribute, remix, adapt, build upon this work non-commercially, and license their derivative works on different terms, provided the original work is properly cited, appropriate credit is given, any changes made indicated, and the use is non-commercial. See: http://creativecommons.org/licenses/by-nc/4.0/.

Correction notice Author name Giuseppe Biondi-Zoccai has been corrected and affiliation 3 has been added. 
ORCID iD

Istvan Kecskes http://orcid.org/0000-0002-9688-8125

\section{REFERENCES}

1 Ramezani Y, Mobasheri M, Moosavi SG. Exposure rate of cardiovascular risk factors among clients of health-care clinics in Kashan, Autumn 2010. J Shahrekord Univ Med Sci 2011;13:76-82.

2 GBD 2017 Causes of Death Collaborators. Global, regional, and national age-sex-specific mortality for 282 causes of death in 195 countries and territories, 1980-2017: a systematic analysis for the global burden of disease study 2017. Lancet 2018;392:1736-88.

3 Qureshi A, Gurbuz Y, Niazi JH. Biosensors for cardiac biomarkers detection: a review. Sens Actuators B Chem 2012;171-172:62-76.

4 Knuuti J, Wijns W, Saraste A, et al. 2019 ESC guidelines for the diagnosis and management of chronic coronary syndromes. Eur Heart J 2020;41:407-77.

5 World Health Organization. The top 10 causes of death, 2018.

6 Hunt SA, Baker DW, Chin MH, et al. ACC/AHA guidelines for the evaluation and management of chronic heart failure in the adult: executive summary. A report of the American College of Cardiology/ American heart association Task force on practice guidelines (Committee to revise the 1995 guidelines for the evaluation and management of heart failure). J Am Coll Cardiol 2001;38:2101-13.

7 Sowden E, Hossain M, Chew-Graham C, et al. Understanding the management of heart failure with preserved ejection fraction: a qualitative multiperspective study. Br J Gen Pract 2020;70:e880-9.

8 Hwang I-C, Cho G-Y, Yoon YE, et al. Different effects of SGLT2 inhibitors according to the presence and types of heart failure in type 2 diabetic patients. Cardiovasc Diabetol 2020;19.

9 Taylor CJ, Rutten FH, Brouwer JR, J.R. Brouwer, FD.R, et al. Practical guidance on heart failure diagnosis and management in primary care: recent EPCCS recommendations. Br J Gen Pract 2017;67:326-7.

10 Rutten FH, Gallagher J. What the general practitioner needs to know about their chronic heart failure patient. Card Fail Rev 2016;2:79-84.

11 Troxel D, Rannum D, Robin D, et al. Nurse practitioner closed claim study, the doctors company, thedoctors.com 2017.

12 Bassan R. Chest pain units: a modern way of managing patients with chest pain in the emergency department. Arq Bras Cardiol 2002;79:203-9.
13 Bennett G, O'Donnell CJ, Coady S. 2013 ACC/AHA guideline on the assessment of cardiovascular risk 2013.

14 Pellikka PA, She L, Holly TA, et al. Variability in ejection fraction measured by echocardiography, gated single-photon emission computed tomography, and cardiac magnetic resonance in patients with coronary artery disease and left ventricular dysfunction. JAMA Netw Open 2018;1:e181456.

15 De Geer L, Oscarsson A, Engvall J. Variability in echocardiographic measurements of left ventricular function in septic shock patients. Cardiovasc Ultrasound 2015;13:1-8.

16 Massel D. Observer variability in ECG interpretation for thrombolysis eligibility: experience and context matter. J Thromb Thrombolysis 2003;15:131-40.

17 Wagenvoort LME, Willemsen RTA, Konings KTS, et al. Interpretations of and management actions following electrocardiograms in symptomatic patients in primary care: a retrospective dossier study. Neth Heart J 2019;27:498-505.

18 Falces C, Andrea R, Heras M, et al. [Integration between cardiology and primary care: impact on clinical practice]. Rev Esp Cardiol 2011;64:564-71.

19 Pallikadavath S, Patel R, Sarania R, et al. Palpitation referrals from primary care to a secondary care cardiology outpatient clinic: assessing adherence to guidelines. Fam Pract 2021;38:127-31.

20 Quanjel TCC, Struijs JN, Spreeuwenberg MD, et al. Shifting hospital care to primary care: an evaluation of cardiology care in a primary care setting in the Netherlands. BMC Fam Pract 2018;19:1-8.

21 Bottle A, Kim D, Aylin P, et al. Routes to diagnosis of heart failure: observational study using linked data in England. Heart 2018;104:600-5.

22 Clinical Performance Assessment: Considerations for ComputerAssisted Detection Devices Applied to Radiology Images and Radiology Device Data- Premarket Approval (PMA) and Premarket Notification 510(k) Submission. Available: https://www.fda.gov/ regulatory-information/search-fda-guidance-documents/clinicalperformance-assessment-considerations-computer-assisteddetection-devices-applied-radiology

23 E9(R1) Statistical Principles for Clinical Trials: Addendum: Estimands and Sensitivity Analysis in Clinical Trials, to determine the suitable statistical analysis we are going to use in our CS. Available: https:// www.fda.gov/downloads/Drugs/GuidanceComplianceRegulatorylnfo rmation/Guidances/UCM582738.pdf 


\section{Correction: Novel tech throws knock-out punch to ECG improving GP referral decisions to cardiology}

Calcagno S, Biondi-Zoccai G, Stankovic T, et al. Novel tech throws knock-out punch to ECG improving GP referral decisions to cardiology. Open Heart 2022;9:e001852. doi:10.1136/openhrt-2021-001852

Author name Giuseppe Biondi-Zoccai name has been corrected and their second affiliation has been added: Mediterranea Cardiocentro, Napoli, Italy.

Open access This is an open access article distributed in accordance with the Creative Commons Attribution Non Commercial (CC BY-NC 4.0) license, which permits others to distribute, remix, adapt, build upon this work non-commercially, and license their derivative works on different terms, provided the original work is properly cited, appropriate credit is given, any changes made indicated, and the use is non-commercial. See: http://creativecommons.org/licenses/by-nc/4.0/.

C Author(s) (or their employer(s)) 2022. Re-use permitted under CC BY-NC. No commercial re-use. See rights and permissions. Published by BMJ.

Open Heart 2022;9:e001852corr1. doi:10.1136/openhrt-2021-001852corr1

(A) Check for updates 